\title{
Assessment of rainfall variability and its impact on groundnut yield in Bundelkhand region of India
}

\author{
Akram Ahmed ${ }^{1, *}$, Dibyendu Deb ${ }^{2}$ and Surajit Mondal ${ }^{1}$ \\ ${ }^{1}$ ICAR Research Complex for Eastern Region, ICAR Parisar, P. O. Bihar Veterinary College, Patna 800 014, India \\ ${ }^{2}$ Indian Grassland and Fodder Research Institute, Near Pahuj Dam, Gwalior Road, Jhansi 284 003, India
}

Bundelkhand region, one of the vulnerable areas in central India, is prone to frequent drought and crop failure due to annual rainfall variability. In this study, long-term (113 years) fine resolution $\left(0.25^{\circ} \times 0.25^{\circ}\right)$ daily gridded rainfall data has been analysed to depict a spatial variation of annual rainfall over Bundelkhand. An increase in annual rainfall has been observed from north to south of the study area. A declining trend varying from 0.49 to $2.16 \mathrm{~mm}$ per year is observed in annual rainfall time series in most parts of the study area. Trend analysis of monsoon rainfall shows overall declining trend over the study area. Rainfall events are categorized in various classes and their spatial trends over Bundelkhand are depicted. Kharif crop calendar (July-September) as well as its yield in India, including Bundelkhand, is primarily based on monsoonal rainfall parameters. A study on the relationship between groundnut yield and monsoonal rainfall parameters for Jhansi district in Bundelkhand shows highest correlation (0.46) between groundnut yield and rainfall class 3 events $(16 \leq$ rainfall intensity, $\mathrm{mm} \mathrm{day}^{-1}<32$ ) occurred in a year followed by cumulative rainfall amount precipitated during June-July (JJ). The frequency of rainfall class 5 type $\left(64 \leq\right.$ rainfall intensity, $\left.\mathrm{mm} \mathrm{day}^{-1}<128\right)$ as well as a delay in onset of monsoonal rainfall have shown a negative correlation with groundnut yield. This study depicts rainfall pattern over the study area and identifies the vulnerable areas that are likely to experience more water stress due to rainfall variability.

Keywords: Bundelkhand region, groundnut yield, Indian monsoon rainfall, rainfall intensity class.

DEVIATION from normal rainfall in a region has an immense effect on the availability of water resources for agriculture ${ }^{1}$. In spite of recent advances in technologies, weather and climate are still the deciding factors for agricultural production ${ }^{2}$. Variability of climatic parameters such as precipitation and temperature, etc. affects crop growth stages and thus, influences the crop yield. In crop season, deviation in timing of seasonal rainfall puts far-

\footnotetext{
*For correspondence. (e-mail: akrambckv@gmail.com)
}

mers in surmise to opt for the right time for sowing crop seeds and applying agricultural inputs ${ }^{3}$. New challenges are arising such as increased intensity of infestation of diseases in crops and propagation of new crop diseases etc. due to the climatic variability ${ }^{4}$. The frequency of natural hazards, particularly drought and flood events, has been increased worldwide ${ }^{5}$. Many a time, high-intensity rainfall events that occur in the offseason cause huge crop damage and put farmers in economic stress. According to the Fifth Assessment Report of Intergovernmental Panel on Climate change ${ }^{6}$, the global average surface temperature over India will rise from $1.7^{\circ} \mathrm{C}$ to $2.2^{\circ} \mathrm{C}$ in the $2030 \mathrm{~s}$ compared to $1970 \mathrm{~s}$, along with the increase in the number of monsoon break days and extreme rainfall events. Rising mean and diurnal temperature and frequent occurrences of extreme precipitation events are reported in many parts of the world ${ }^{7-10}$. Decline in the number of monsoon break days ${ }^{11}$ and monsoon depressions ${ }^{12}$, spatiotemporal analysis of annual and seasonal rainfall ${ }^{13}$ and drought intensity and its frequency ${ }^{14-16}$ over India has been studied extensively and some of them tried to link these parameters with changing climate $^{14}$. It has been predicted that freshwater availability in most of the big Indian rivers will decrease due to climate change and the probable change of water resources for major Indian river basins have been quantified ${ }^{17}$.

Many researchers have carried out region-specific rainfall trend analysis over India particularly over its central part. Kumar et al. ${ }^{18}$ reported a declining trend of annual rainfall over central India and north-east India, and an increase in annual rainfall in other parts of India while analysing rainfall data for the period 1871-2005. Rajeevan et al. ${ }^{19}$ observed an increasing trend of extreme rainfall events in the last five decades over central India which is attributed to the increasing trend of sea surface temperature. Increase in extreme rain events has also been reported over central India by many workers ${ }^{20,21}$. Various studies reported the effect of rainfall variability on crop yield. Several workers observed a strong correlation between Indian summer monsoon rainfall and food grain production over India ${ }^{22-24}$. Selvaraju ${ }^{25}$ and Subash et $a l .{ }^{26}$ studied the effect of Indian monsoon rainfall on rice productivity over India. They showed that Indian 
monsoon rainfall is greatly affected by El Niño events and reported up to maximum $21.9 \%$ reduction in rice productivity in an El Niño year.

The present study is carried out over Bundelkhand region, located in the central part of India which often faces drought as a result of inter-annual rainfall variability. Several studies have been carried out on Bundelkhand region focusing on trend analysis of long-term rainfall $^{27-31}$. Most of these studies analysed rainfall data of few observed rainfall stations and drew conclusions on rainfall variability using the coarse resolution data. These studies lack systematic analysis of various rainfall class types. In our study, the continuous spatial variation of annual and monsoonal rainfall and its trend over the Bundelkhand region has been carried out based on fine resolution $0.25^{\circ} \times 0.25^{\circ}$ gridded rainfall data derived from more than 70 observed rainfall stations. Particular rain class types are important form the agricultural point of view. Rainfall events are categorized into various classes and spatial variation of their trend is shown in this study. Groundnut is one of the important kharif crops of Bundelkhand often affected by rainfall variability $^{32}$. As a case study, the correlation coefficient between groundnut yield and various rainfall parameters was determined for Jhansi district to help in understanding the dependency of groundnut yield on various rainfall parameters.

\section{Materials and methods}

\section{Study area}

Bundelkhand region located in the central part of India comprises seven districts of Uttar Pradesh and six districts of Madhya Pradesh (Figure 1). The districts that belong to the state of Uttar Pradesh are Jhansi, Lalitpur, Mahoba, Chitrakoot, Banda, Hamirpur, and Jalaun while the districts Sagar, Damoh, Chhatarpur, Tikamgarh, Panna, and Datia come under Madhya Pradesh. The total geographical area of Bundelkhand is 7.16 million hectare (Mha) and lies between $23^{\circ} 20^{\prime} \mathrm{N}$ and $26^{\circ} 20^{\prime} \mathrm{N}$ lat. and $78^{\circ} 20^{\prime} \mathrm{E}$ and $81^{\circ} 40^{\prime} \mathrm{E}$ long. It is predominantly an agrarian economy as about $82 \%$ of its population depends on agriculture $^{15}$. Cereals $(54.6 \%)$ are the major agricultural produce of this area followed by pulses $(32.4 \%)$, oilseeds $(8.0 \%)$, sugarcane $(0.2 \%)$ and other crops $(4.8 \%)$ for normal rainfall years. Major soils of this region include alluvial, medium black, and mixed red and black soils. The topography of the region is characterized by rugged landscape, shallow soil depth with frequent presence of rocky outcrops and boulder-strewn plains. Bundelkhand region comes under the semi-arid region and faces acute water shortage mostly during summer due to the poor water holding capacity of the soils. A vast part of the agricultural area of Bundelkhand is rainfed and major crops cultivated during kharif (monsoon season) are groundnut, soybean, urad, moong, sesamum, etc.

\section{Data used}

Gridded daily rainfall data of resolution $0.25^{\circ} \times 0.25^{\circ}$ for the period 1901-2013 (113 years) procured from the India Meteorological Department (IMD) is used in this study. Details of this gridded rainfall data are given in Rajeevan et al. ${ }^{19}$. IMD is the nodal agency in India for recording and distributing the meteorological data. This gridded rainfall data is prepared from the groundobserved rainfall of various stations using the technique suggested by Shepard ${ }^{33}$. Rainfall data of 156 grids spread uniformly over Bundelkhand and its $30 \mathrm{~km}$ buffer area are analysed, out of which 53 grids fall outside the actual boundary of Bundelkhand. The quality of rainfall time series data at each grid is checked thoroughly for consistency as well as missing rainfall data by IMD before its distribution for use. Apart from rainfall analysis, this study also aims to assess the impact of various rainfall parameters such as rainfall amount, rainfall event size, number of rainy days, etc. on groundnut production. Groundnut is one of the major cultivated crops of kharif in Jhansi district and also due to easy access of the agricultural data, groundnut yield data for 1991-2013 were

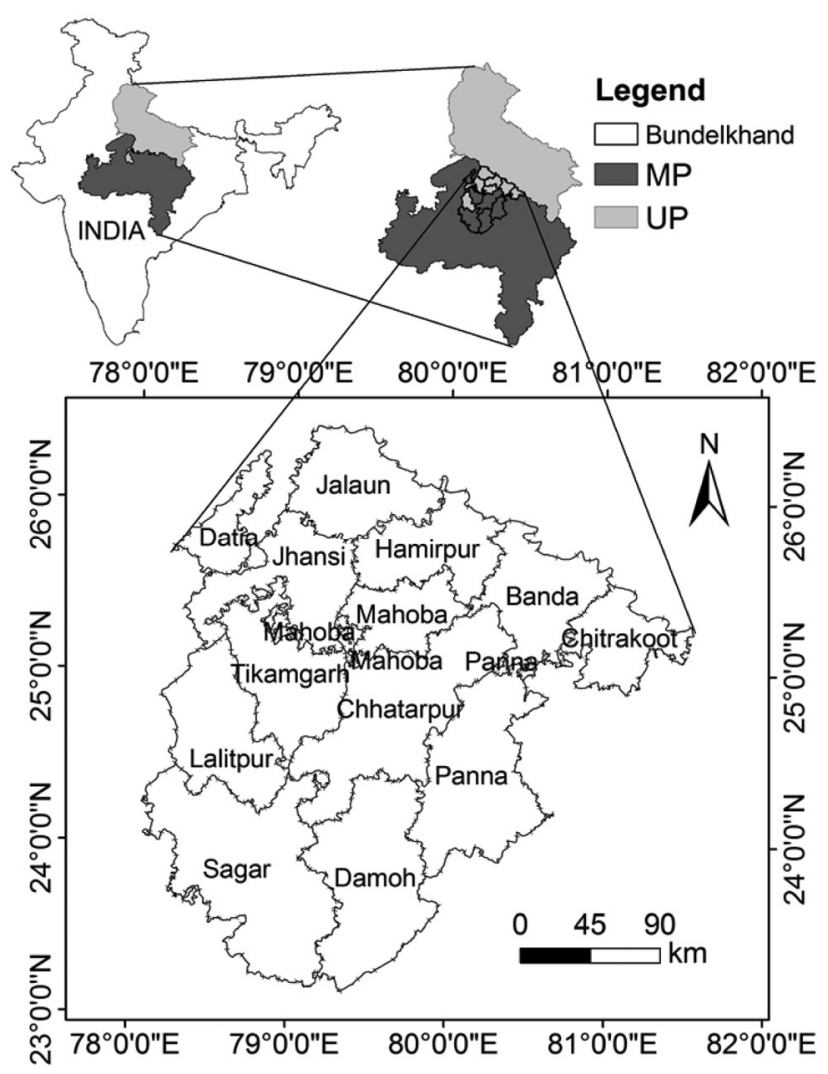

Figure 1. Location map of the study area. 
collected from the district Agricultural Office Jhansi, Government of Uttar Pradesh, India.

\section{Testing homogeneity of time series data}

Homogeneity tests check whether a time series belongs to one population with a time-invariant mean or changes occur in the time series with time. Non-homogeneity in time series occurs when there is a change in the method of data recording or change in environmental conditions $^{34}$. Cumulative deviation test is one of the robust statistical tests used widely for checking homogeneity in time series data ${ }^{35}$. The null hypothesis assumes that the time series variable has the same mean whereas the alternate hypothesis assumes that the mean of the series changes with time ${ }^{36}$. Homogeneity of a time series is tested using the test statistic, $Q$, which is written as

$$
\begin{gathered}
Q=\max _{0 \leq k \leq N}\left|S_{k}^{* *}\right|, \\
\text { where } S_{k}^{* *}=\left(S_{k}^{*} / S_{x}\right), \\
S_{k}^{*}=\sum_{t=1}^{k}\left(x_{t}-\bar{x}\right),
\end{gathered}
$$

where $S_{x}, x_{t}, \bar{x}$ and $N$ are the sample standard deviation, data value, mean of the data series and number of data values respectively. A high value of $Q$ implies nonhomogeneity of the time series. Critical values of $Q / \sqrt{N}$ are given in Buishand ${ }^{37}$.

\section{Trend analysis}

In this study, Modified Mann-Kendall (MMK) test $\mathrm{t}^{38}$ along with Theil-Sen estimator ${ }^{39,40}$ is used for trend analysis of annual and seasonal rainfall time series data of 113 years at taluk scale (a taluk is a subdivision of a district comprising of several villages) of Bundelkhand. A positive value of the MMK test statistic $(Z)$ signifies an increasing or upward trend whereas its negative value suggests a declining trend of the time series variable. If $|Z|>Z_{1-\alpha / 2}$, the null hypothesis $\left(H_{0}\right)$ of no trend in the time series is rejected at significance level $\alpha=0.05$. $Z_{1-\alpha / 2}$ is the value of standard normal variate with a probability of exceedance of $\alpha / 2$.

If a linear trend exists in the time series data, the magnitude of the positive or negative trend is estimated by a non-parametric test, known as Theil-Sen estimator. Positive and negative signs of the test statistic of Theil-Sen estimator suggest increasing and decreasing trend in the time series.

In addition, daily rainfall data of each year of each grid has been categorized into six rainfall intensity classes based on Alpert et al. $^{41}$. Time series consisting of data of annual occurrence of each rainfall class at each grid (hereafter referred as rainfall class) is also assessed for trend. Inverse distance weighting interpolation method ${ }^{42}$ is used for representing the spatial variation of annual rainfall and its trend. In addition, the spatial variation of the trend of each rainfall class is shown over the study area. Monsoonal rainfall is the backbone of kharif agriculture (July-September) in Bundelkhand. Any significant deviation of normal monsoonal rainfall will have an obvious impact on agricultural production vis-à-vis the economy of an area, particularly for south-east Asia. To depict an overview of the monsoonal rainfall trend over Bundelkhand, five representative districts, viz. Jhansi, Panna, Hamirpur, Sagar, and Chhatarpur (hereafter analysis carried out jointly on these districts referred to as representative Bundelkhand region) located in the east, west, north, south and central part respectively, of the Bundelkhand region are chosen. The rainfall grid located nearest to the respective district headquarters of the representative Bundelkhand ( $\mathrm{RB}$ ) region is assumed to be representing the rainfall of that district.

\section{Correlation analysis}

In order to determine the relationship between various rainfall parameters and groundnut yield, the correlation coefficient is used here. Statistical $Z$-score as discussed by Jain et $a l .^{31}$ is used in this study to represent the monsoonal rainfall. $Z$-score is presented as

$$
Z \text {-score }=\frac{x_{i}-\bar{x}}{\sigma}
$$

where $x_{i}$ is yearly monsoonal rainfall, $\bar{x}$ is the average monsoonal rainfall and $\sigma$ is the standard deviation of the monsoonal rainfall. Similarly, $Z$-score is calculated for cumulative rainfall that occurred in June-July months. It is the observation of farmers of Jhansi that monsoonal rainfall starts in Jhansi mostly in the last week of June. Normally, the climate in the last week of June or first week of July is favourable for sowing groundnut in Jhansi subject to the normal occurrence of monsoon. Due to the occurrence of monsoonal rainfall in the last week of June or first week of July, soil moisture stock in root zone increases which allow farmers to sow groundnut at Jhansi condition. Availability of soil moisture in sufficient quantity in the root-zone depth of groundnut plant is important for germination of groundnut seed ${ }^{43}$. Hence, it is assumed that normal occurrence of total rainfall in June and July (JJ) is also important than total monsoonal rainfall for optimum groundnut production. Groundnut crop requires about $500-700 \mathrm{~mm}$ of water for its optimum production in various places in semi-arid conditions of India $^{44}$. Long-term average monsoonal rainfall at Jhansi 
is reported to be about $800 \mathrm{~mm}$, which is apparently sufficient for groundnut production, subject to the normal occurrence of monsoonal rainfall amount and its proper distribution throughout the monsoon season. It is also reported that excess rainfall affects in varying degree in different stages of groundnut plant particularly during seedling followed by vegetative stage ${ }^{45}$. Hence, rainfall parameters, viz. rainfall amount in monsoon and $\mathrm{JJ}$, occurrences of a number of rainfall events of varying intensities in $\mathrm{JJ}$ and delay in monsoon onset date from normal will have a varying effect on optimum groundnut yield. To understand the influence of these rainfall parameters on groundnut production, a correlation study was carried out between groundnut production and each of the rainfall parameters for Jhansi district. Rainfall parameters for Jhansi district were computed by taking an average of the rainfall parameters corresponding to each rainfall grid falling within the periphery of Jhansi district.

\section{Results and discussion}

\section{Homogeneity}

It is a tedious job to check the consistency in all the time series data for 156 grids. Hence, consistency in all the time series data corresponding to the rainfall grids standing for RB region was tested for homogeneity as an arbitrary check. It was observed that the values of cumulative deviation test statistics $(Q / \sqrt{N})$ for all the time series were within the critical limit (value of the critical limit of cumulative deviation test statistics for sample size 113 is 1.30) except for the time series of Panna and Chhatarpur (Table 1). Values of the homogeneity test statistics are well below the critical limit for the annual and monsoonal rainfall, which indicates no significant change in the rainfall pattern over the study years. However, homogeneity test statistics values for the time series for rainfall class 1 for Panna and Chhatarpur indicate a change in annual occurrence of rainfall class 1 events. Hence, the results of the homogeneity test prove overall consistency in the time series data.

\section{Annual rainfall variation and its trend analysis}

It is observed from the analysis of annual rainfall time series data that average annual rainfall over Bundelkhand varies from lowest $760 \mathrm{~mm}$ to highest $1227 \mathrm{~mm}$ at Datia and Damoh districts respectively (Figure $2 a$ ). Increase in annual rainfall amount is observed from north to south of the study area. The occurrence of higher mean annual rainfall in southern districts of Bundelkhand and lowest mean annual rainfall in Datia district is also reported by Jana et $a l .{ }^{31}$ while analysing district-wise monthly rainfall time series over the period 1901-2000. Trend analysis of annual rainfall time series shows a decreasing trend almost throughout Bundelkhand except in few places of Datia and Sagar districts where an insignificant increasing trend in annual rainfall has been observed (Figure $2 \mathrm{~b}$ ). The highest declining trend of $2.16 \mathrm{~mm}$ per year in annual rainfall was observed in Hamirpur taluk of Hamirpur district; Banda, Baberu, Karwi and Mau taluks of Banda district and Lauri taluk of Chhatarpur district, whereas lowest declining trend of $0.49 \mathrm{~mm}$ per year was observed in Jhansi and Mau Ranipur taluks of Jhansi district; Nivari and Jatara taluks of Tikamgarh district; Lalitpur taluk of Lalitpur district; Khurai and Rehli taluks of Sagar district and Damoh taluk of Damoh district. The increasing trend of $0.42 \mathrm{~mm}$ per year in annual rainfall is observed in Datia and Seondha taluks of Datia district and Sagar taluk of Sagar districts. The increasing trend of annual rainfall in Datia district is also reported by Rai et $a{ }^{27}$ while analysing the annual rainfall of 1942-2008. Figure $2 b$ also depicts maximum declining trend in annual rainfall in north, north-east and eastern parts of Bundelkhand comprising of Jalaun, Hamirpur, Banda, Chitrakoot, Panna, and parts of Mahoba districts which complies with the findings of Jana et $a l .{ }^{31}$. National committee on the development of backward areas during 1981 also declared these districts as drought-prone areas based on the criteria if precipitation occurs in significantly less quantity in main crop season in three years out of every 10 years (www.bundelkhandinfo.org.in). Around $89 \%$ and $11 \%$ of total 156 grids show declining and increasing trend, respectively, in annual rainfall time series (Figure $2 c$ ). A significant $(P<0.05)$ declining trend is observed in $32 \%$ grids mostly located in the north, northeast and eastern part of the Bundelkhand (Figure $2 \mathrm{~b}$ ). Around $56 \%$ of the total grids showing significant declining trend as shown in Figure $2 b$ were located within the geographical boundary of Bundelkhand.

Although Jana et al. $^{31}$ reported an increasing trend of annual rainfall in most of the districts of Bundelkhand under Uttar Pradesh, our findings of the declining trend of annual rainfall comply with the findings of most researchers ${ }^{14,29}$. However, declining trend of annual rainfall in Bundelkhand districts of Madhya Pradesh is invariably reported by all researchers ${ }^{15,27,31}$. Rainfall break of 10 days or more during monsoon with a frequency of equal to or more than one is common invariably in every year in every district of Bundelkhand. It affects the rainfed agriculture of Bundelkhand and hence provision of supplemental irrigation is recommended for optimum crop production under this changing rainfall scenario ${ }^{14}$.

\section{Monthly rainfall variation and monsoonal rainfall trend}

Monthly rainfall time series is derived from monthly average rainfall of the grids corresponding to the $\mathrm{RB}$ region. Figure $3 a$ shows the monthly distribution of rainfall over RB. It is observed that on an average about $90 \%$ 
Table 1. Cumulative deviation test statistics $(Q / \sqrt{N})$ for various time series

\begin{tabular}{lccccc}
\hline & \multicolumn{3}{c}{$Q / \sqrt{N}$} \\
\cline { 2 - 6 } Time series & Jhansi & Panna & Hamirpur & Sagar & Chhatarpur \\
\hline Annual rainfall & 0.20 & 0.80 & 1.07 & 0.99 & 0.23 \\
Monsoonal rainfall & 0.37 & 0.79 & 1.05 & 0.93 & 0.18 \\
Annual occurrences of rainfall class 1 & 0.72 & $\mathbf{1 . 8 6}$ & 0.99 & 0.76 & $\mathbf{1 . 4 2}$ \\
Annual occurrences of rainfall class 2 & 1.30 & 0.46 & 0.60 & 0.72 & 0.84 \\
Annual occurrences of rainfall class 3 & 0.34 & 0.31 & 0.66 & 0.48 & 0.60 \\
Annual occurrences of rainfall class 4 & 0.55 & 0.99 & 0.46 & 1.08 & 0.56 \\
Annual occurrences of rainfall class 5 & 0.50 & 0.34 & 0.58 & 0.82 & 0.37 \\
Annual occurrences of rainfall class 6 & 0.39 & 0.75 & 0.52 & 0.35 & 1.05 \\
\hline
\end{tabular}

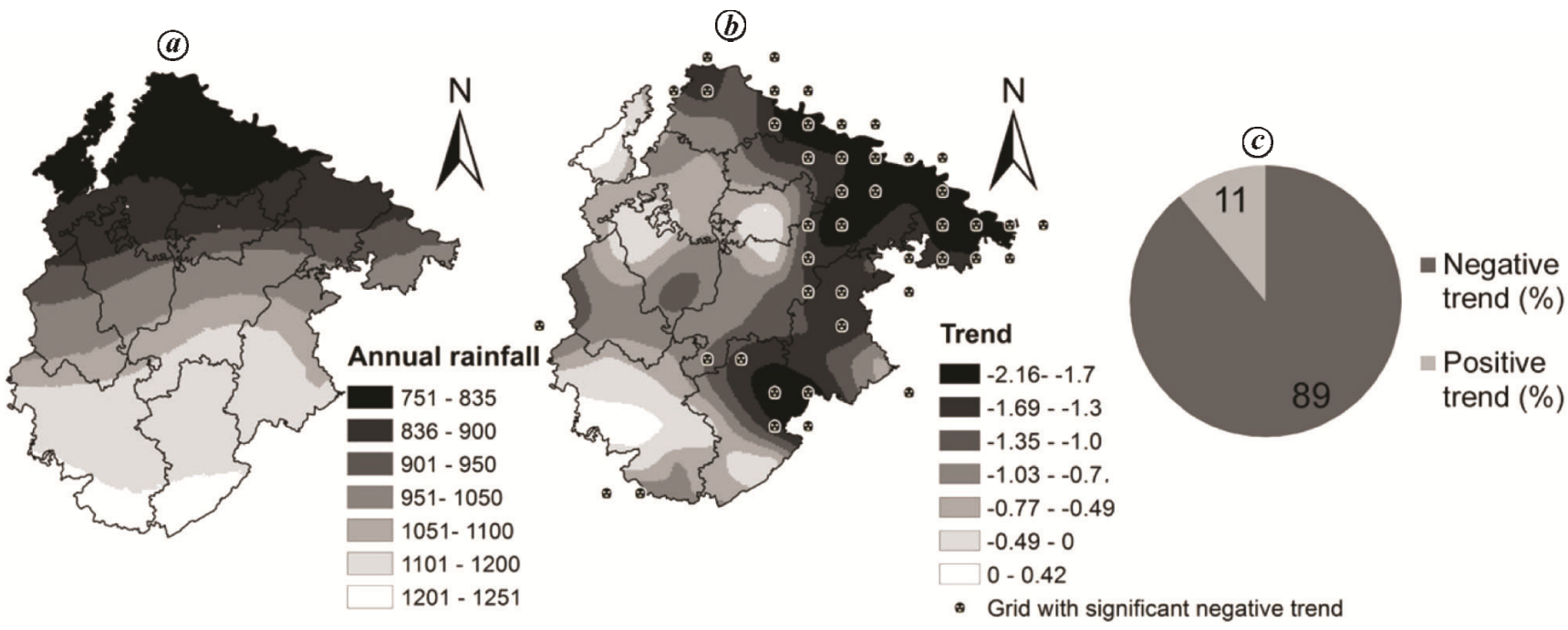

Figure 2. $\boldsymbol{a}$, Spatial variation of annual rainfall in $\mathrm{mm} ; \boldsymbol{b}$, its trend (mm per year); $\boldsymbol{c}$, pie chart representing percentage of grids following positive and negative trends over the study area.

of the annual rainfall occurs during the monsoon season (July-September). Specifically, monsoonal rainfall in Bundelkhand is concentrated in two months, viz. July and August. However, it has been observed that maximum monthly rainfall occurs in August (Figure $3 a$ ). Trend analysis of monsoonal rainfall over the $\mathrm{RB}$ region reveals its declining trend at all places except Sagar (Figure $3 b$ ). A significant $(P<0.05)$ declining trend in monsoonal rainfall was observed in Jhansi and Hamirpur $(1.44 \mathrm{~mm}$ per year). A declining trend in monsoonal rainfall was observed at Panna (1.06 mm per year) and Chhatarpur $(0.74 \mathrm{~mm}$ per year), whereas an insignificant $(P<0.05)$ increasing trend in monsoonal rainfall of $0.53 \mathrm{~mm}$ per year was observed in Sagar district. A significant falling trend of monsoonal rainfall in other districts such as Chitrakoot and Mahoba was reported by Thomas et al. ${ }^{15}$. Like annual rainfall, falling rainfall trend in monsoon season as reported by our study and most other studies ${ }^{18,29}$ contradicts the findings of an increasing trend in monsoonal rainfall by Jana et al. ${ }^{31}$. The increasing trend of rainfall in pre-monsoon (March-June) and declining trend in the rest of the seasons in Bundelkhand was reported by Rai et al. ${ }^{28}$ and Thomas et al. ${ }^{14}$. It is reported that the amount of monsoonal rainfall has become half of its long-term normal amount during the last two decades resulting in continuous drought lasting for 4-5 years. This has caused repeated crop failures and farmers are forced to migrate to nearby big cities for work as daily labourers ${ }^{46}$. Bundelkhand is also known for its drinking water crisis. Women used to travel long distances to fetch drinking water. It is reported that a decrease in rainfall in Bundelkhand caused inadequate groundwater recharge resulting in dying of hand pumps and wells which are the main sources of drinking water. Thus, water scarcity for drinking and crop production due to occurrence of inadequate rainfall has caused the life of Bundelkhand people to be more stressful ${ }^{47}$.

\section{Trend analysis of rainfall classes}

Time series of rainfall classes corresponding to each grid for the whole of Bundelkhand comprises of 156 grids and representative Bundelkhand region comprises of 5 grids 
were prepared. In addition, another six time series corresponding to six rainfall classes were prepared by taking the average of the respective rainfall class for the grids representing the RB region for frequency analysis or calculation of annual occurrence of the respective rainfall classes (Figure 4). Light to moderate intensity rainfall classes (class 1: intensity $<4 \mathrm{~mm}^{-1 a y}{ }^{-1}$, class 2 : intensity $<16 \mathrm{~mm} \mathrm{day}^{-1}$ and class 3 : intensity $<32 \mathrm{~mm} \mathrm{day}^{-1}$ ) were observed more than the high intensity rainfall classes (class 4: intensity $<64 \mathrm{~mm} \mathrm{day}^{-1}$, class 5 : intensity $<$ $128 \mathrm{~mm} \mathrm{day}^{-1}$ and class 6 : intensity $\geq 128 \mathrm{~mm} \mathrm{day}^{-1}$ ). On an average, the frequency of class 1 was observed to be 42 whereas, the frequency of classes 2 to 5 was observed to be $30,12,6$ and 2 respectively, in a year. The occurrence of class 6 rainfall type was rarely observed. While analysing the trend of time series of rainfall classes, it has been observed that frequency of light to moderate rainfall class types, viz. classes 1 to 3 follow a declining trend in most places of Bundelkhand (Figure $5 a-c)$. The declining trend is observed in 99,86 and 75 grids out of 156 grids for rainfall classes 1, 2, and 3 respectively, of which 86,57 and $53 \%$ grids have shown a significant declining trend for these rainfall classes. The

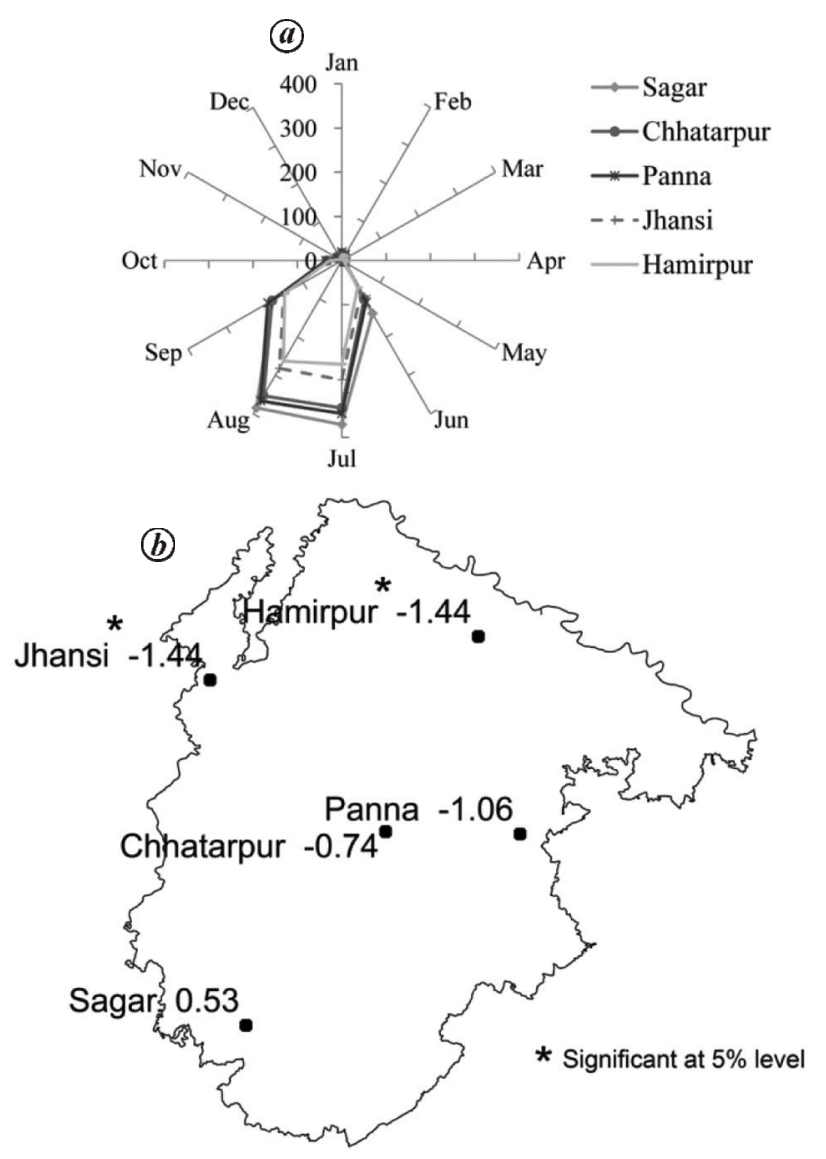

Figure 3. $\boldsymbol{a}$, Normal monthly rainfall in $\mathrm{mm} ; \boldsymbol{b}$, monsoonal rainfall trend over representative Bundelkhand region. declining trend of rainfall class 4 is observed in 55 grids of which $69 \%$ grids showed a significant declining trend. These grids are mostly located in north-east and southeast part of Bundelkhand. Figure $5 d$ shows that no trend (value of Sen slope estimator equal to zero) in rainfall class 4 exists in the vast area of Bundelkhand. An increasing trend exists in rainfall classes 1 and 2 in a significant part of the districts of Bundelkhand namely Datia, Jhansi, Hamirpur, Mahoba, and Banda comprising of 31 grids each, of which $55 \%$ and $67 \%$ grids respectively, have shown an increasing trend (Figure $5 a$ and $b$ ). Few places located in the central part of Bundelkhand have shown an increasing trend for the rainfall classes 3 and 4, although none of the grids have shown significant increasing trend for class 3 . However, only a single grid has shown significant increasing trend for class 4 (Figure $5 c$ and $b$ ). Almost no trend for rainfall class 5 was observed throughout Bundelkhand except at two grids, of which one grid has shown significant decreasing trend, and the other has shown nonsignificant increasing trend (Figure $5 a$ ). It was observed that the occurrence of rainfall class 6 type is very less for the study period. Hence, no trend was observed for rainfall class 6 in any of the grids. There has been no systematic study carried out on trend analysis of a number of rainy days over the study region previous to our study. The overall declining trend of rainy days as found in our study was supported by farmers' perception of a decrease in number of rainy days reported in various studies ${ }^{48,49}$. The declining trend in rainy days reported in our study supports the truthfulness of prediction made by IPCC ${ }^{6}$.

\section{Monsoon onset date analysis}

Monsoon onset date for 113 years for the RB region was worked out based on the method followed by the IMD described in Rakhecha and $\operatorname{Singh}^{50}$. The normal onset date of monsoonal rainfall in India where the monsoonal rainfall reaches first is 1 st June. Then it subsequently progresses to other parts of India. It has been observed from rainfall data analysis that monsoonal first shower invariably occurs in Sagar district and at the end in Hamirpur district of the RB region. Average date of onset of monsoon in Sagar and Hamirpur districts is calculated to be 18th June and 25th June with standard deviation of 8 and 10 days, respectively, whereas onset date of monsoon for Panna, Chattarpur and Jhansi districts is calculated to be 20th, 21st and 23rd June with standard deviation of 9 days for each district, respectively. From this analysis, it emerges that monsoonal wind strikes first at south districts of Bundelkhand and within a week it spreads over Bundelkhand. If we calculate the average onset date of the monsoonal shower in Bundelkhand as a whole, it comes out to be 21 st June with a standard deviation of 9 days. Average earliest and latest onset date of 


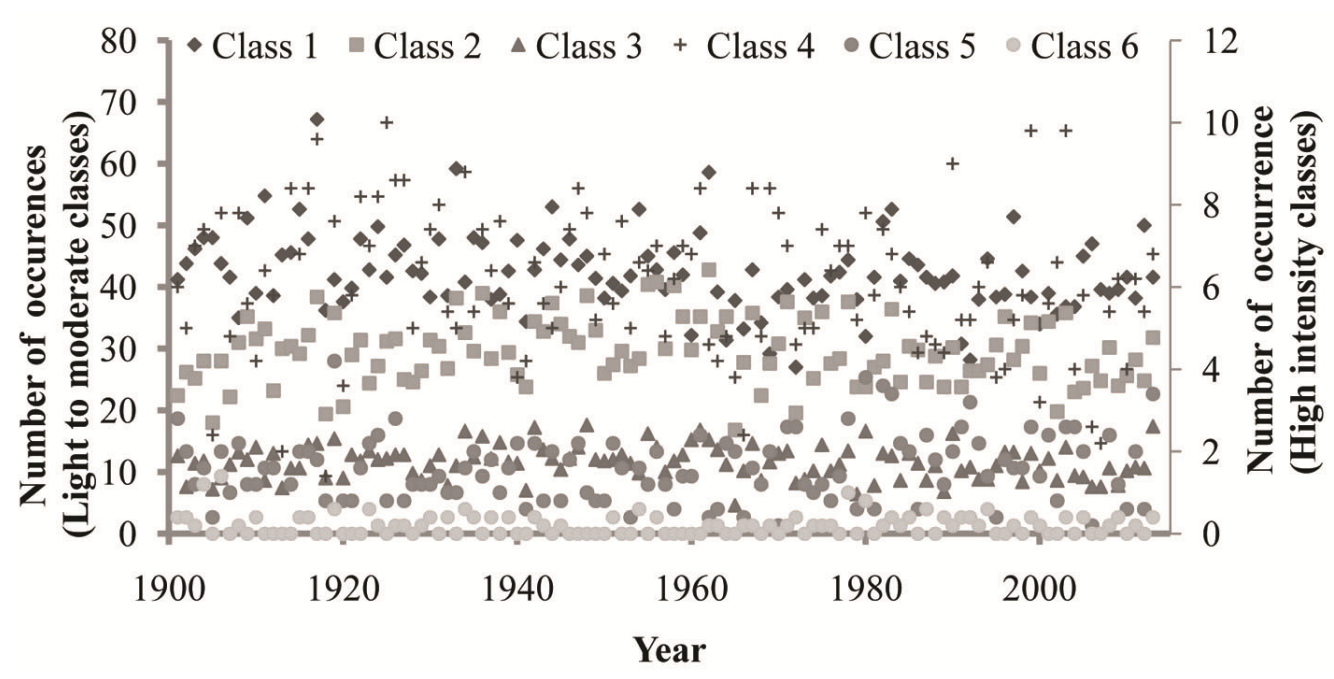

Figure 4. Average annual occurrences of rainfall classes.

monsoonal rainfall over $\mathrm{RB}$ is calculated to be 4th June and 14th July respectively. Normal onset date of monsoonal rainfall in Bundelkhand region of Uttar Pradesh is reported by IMD as 17 th June whereas Deo et al. ${ }^{29}$ reported onset date of monsoonal rainfall for this region as 20th June, both of which invariably support the findings of our study. This study gives a holistic idea with the probable date of onset of monsoonal rainfall in various districts of Bundelkhand which will be helpful to agro meteorologists to advise farmers about the probable suitable date for sowing kharif crops.

\section{Relation between rainfall parameters and groundnut production}

A correlation study was conducted between rainfall parameters considered in this study and groundnut production of Jhansi district for the period 1991-2013. In a study in Nigeria, Adamgbe and $\mathrm{Ujoh}^{51}$ reported a strong correlation between the number of rainy days and rainfall amount with maize yield. In this study, correlation analysis shows that groundnut production is more positively correlated $(0.32)$ with rainfall amount in $\mathrm{JJ}$ than total monsoonal rainfall amount $(0.28)$. This shows more influence of rainfall amount in the $\mathrm{JJ}$ months than the overall monsoonal rainfall on groundnut yield. The onset of monsoon at the end of June and its normal distribution throughout July helps proper germination of groundnut seeds and ensures subsequent healthy growth of the seedlings. The proper onset of monsoonal rainfall and its distribution in JJ provides initial vigour to the plants, which ensures proper development of the groundnut plant in subsequent stages (pegging and pod development stages) subject to optimum rainfall amount and its distribution and other associated inputs. Naveen et al. ${ }^{52}$ reported the effect of water stress during flowering and pegging stage on the reduction of pod yield of groundnut. Kumar et $a .^{22}$ reported a higher correlation (0.64) between groundnut yield and monsoonal rainfall in India. In this study, groundnut yield has shown highest correlation with rainfall class $3(0.46)$ followed by class $2(0.31)$ than class $1(0.10)$ and class $4(0.05)$. It implies more influence of light to moderate intensity rainfall (classes 1 to 3 ) on groundnut yield compared to heavy rainfall class 4 . Groundnut yield has shown a negative correlation with class 5 type $(-0.0006)$ rainfall event. Groundnut crop is susceptible to several diseases and insect pests. Excessive rainfall increases the chances of fungal diseases in groundnut, as a result, its yield reduces ${ }^{53}$. Our result of the negative correlation between groundnut yield and rainfall class 5 indicates the detrimental effect of rainfall class 5 on yield reduction of groundnut. IPCC ${ }^{6}$ has predicted an increase in the number of high-intensity rainfalls over India which might be a concern to groundnut growers. Proper drainage arrangement in the field is required for this unprecedented threat to avoid the negative impact of excess rainfall. Delay in onset of monsoon than the normal in Jhansi was observed to be negatively correlated with groundnut production $(-0.13)$. In this study, monsoon onset date of each year in Jhansi is calculated with reference to its normal onset date of 23 rd June. If monsoonal rainfall starts in a year, before and after $23 \mathrm{rd}$ June, monsoon onset date value of the respective year is considered negative and positive in sign respectively. Late onset of monsoon causes late sowing of groundnut seeds which has significant effect in the reduction in groundnut yield. In a study in South India, Chandrika et al. ${ }^{54}$ reported significant yield reduction in groundnut varieties when they have been sown in the second fortnight of July with respect to the second fortnight of June and the first fortnight of July. 


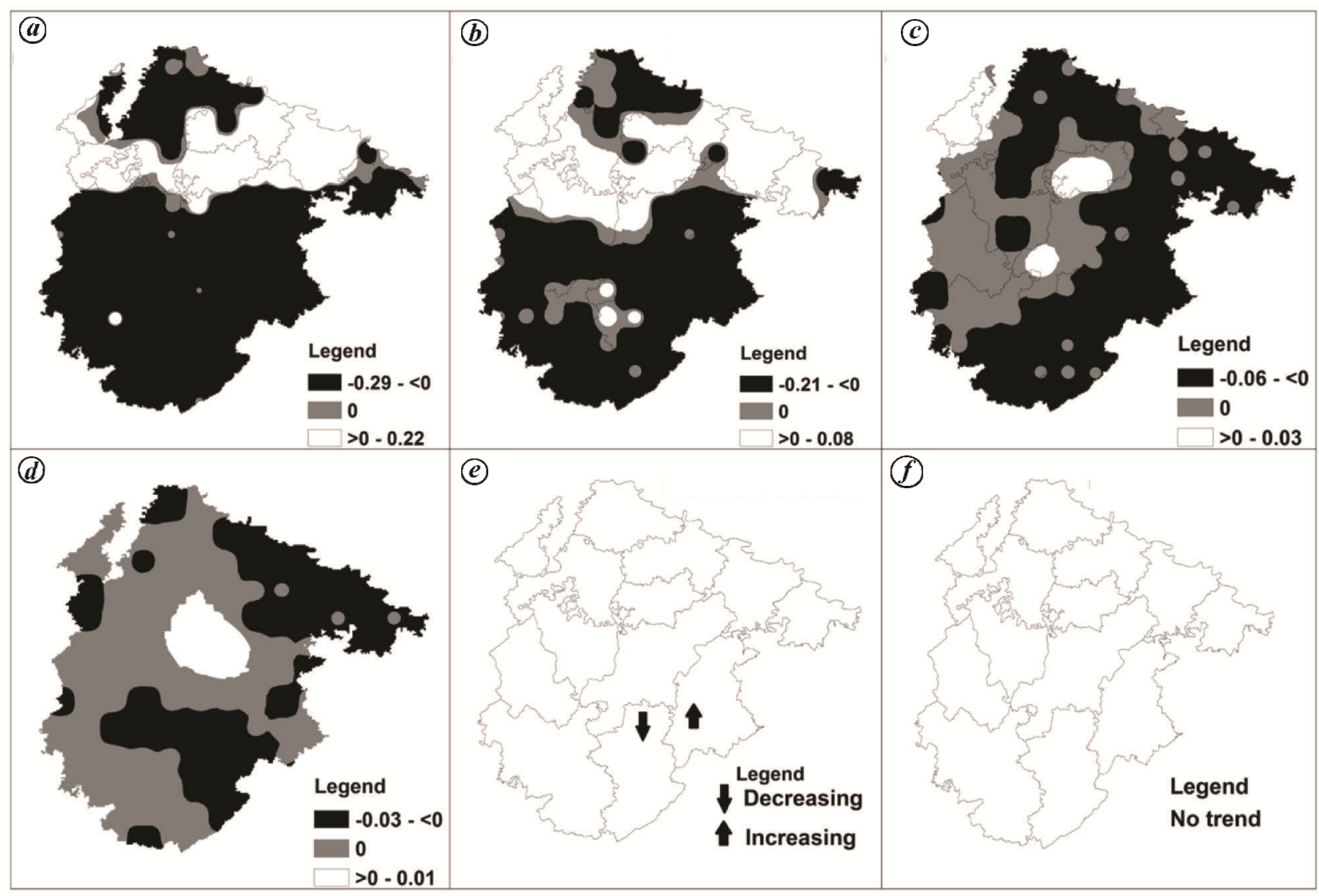

Figure 5. Spatial variation of trend of rainfall: $\boldsymbol{a}$, Class 1; $\boldsymbol{b}$, Class 2; $\boldsymbol{c}$, Class 3; $\boldsymbol{d}$, Class 4; $\boldsymbol{e}$, Class 5; $\boldsymbol{f}$, Class 6 .

The correlation analysis revealed that rainfall classes 2 and 3 , rainfall in $\mathrm{JJ}$ and monsoon have more impact on groundnut yield compared to other rainfall parameters. Though it may be thought that overall increasing trend in rainfall classes 1 and 2 (Figure $5 a$ and $b$ ) and no trend in rainfall classes 3 and 4 (Figure $5 c$ and $d$ ) may have positive impact in sustaining groundnut yield at Jhansi, declining trend of monsoon rainfall will have more negative impact on decreasing productivity of groundnut at Jhansi. Hence, it is expected that sustaining groundnut productivity will be a challenge under changing rainfall scenarios. Trend analysis shows that rainfall classes 3 and 4, which occur 12 and 6 times on an average per year, have shown a declining trend in significant part of Bundelkhand. These rainfall classes are important from the hydrological point of view. Major dams in Bundelkhand are filled by storing the runoff generated especially from these rainfall events. Rabi season (winter) crops, especially wheat, are cultivated using this stored water supplied through the canal in vast areas of Bundelkhand. Hence, the declining trend in a number of these rainfall classes may create water shortage in dams, and supply of water may be restricted particularly during Rabi season (DecemberApril) which can affect the Rabi crops like wheat, berseem, etc.

\section{Conclusion}

This study shows that most of the rainfall occurs in Bundelkhand during monsoon season. Rainfall amount increases from north to south of the study area. Annual rainfall in most parts of Bundelkhand has shown a declining trend. Monsoonal rainfall time series over representative Bundelkhand has also shown an overall declining trend. Light to moderate intensity rainfall classes are observed more than the high-intensity rainfall classes. A declining trend has been observed for light to moderate rainfall classes in most places of Bundelkhand. A declining trend of rainfall class 4 is observed in places located in north-east and south-east part of Bundelkhand. Almost no trend for rainfall classes 5 and 6 is observed throughout the study area. It is observed that the occurrence of rainfall class 6 is very less during the study period. Groundnut yield shows the highest correlation with rainfall class 3 events followed by cumulative rainfall amount precipitated during June-July $(\mathrm{JJ})$, whereas rainfall class 5 type and a delay in onset of monsoonal rainfall are observed to be negatively correlated with groundnut yield for Jhansi district. Results from this study indicate a gradual drying up of Bundelkhand due to irregular rainfall which will be a challenge to sustain crop yield. 
1. Granados, R., Soria, J. and Cortina, M., Rainfall variability, rainfed agriculture and degree of human marginality in North Guanajuato, Mexico. Singapore J. Trop. Geo., 2017, 38, 153-166.

2. Ayoade, J. O., Climate Change, Vantage Publishers, Ibadan, 2004.

3. Bannayan, M., Lotfabadi, S. S., Sanjani, S., Mohamadian, A. and Aghaalikhani, M., Effects of precipitation and temperature on crop production variability in northeast Iran. Int. J. Biometeorol., 2011, 55, 387-401.

4. Gautam, H. R., Bhardwaj, M. L. and Kumar, R., Climate change and its impact on plant diseases. Curr. Sci., 2013, 105, 16851691.

5. López, R. E., Thomas, V. and Troncoso, P., Climate Change and Natural Disasters, STD 414, Santiago, 2015.

6. Core Writing Team, Pachauri, R. K. and Meyer, L. A. (eds), IPCC, Climate change 2014: synthesis report. Contribution of Working Groups I, II and III to the Fifth Assessment Report of the Intergovernmental Panel on Climate Change, Geneva, Switzerland, 2014.

7. Hundecha, Y. and Bárdossy, A., Trends in daily precipitation and temperature extremes across western Germany in the second half of the 20th century. Int. J. Climatol., 2005, 25, 1189-1202.

8. Alexander, L. V. et al., Global observed changes in daily climate extremes of temperature and precipitation. J. Geophys. Res., 2006, 111, 1-22.

9. Volosciuk, C., Maraun, D., Semenov, V. A., Tilinina. N., Gulev, S. K. and Latif, M., Rising Mediterranean sea surface temperatures amplify extreme summer precipitation in central Europe. Sci. Rep., 2006, 6, 32450.

10. Zhao, Y., Xu, X., Huang, W., Wang, Y., Xu, Y., Chen, H. and Kang, Z., Trends in observed mean and extreme precipitation within the Yellow River Basin, China. Theor. Appl. Climatol., 2008; https://doi.org/10.1007/s00704-018-2568-4.

11. Kumar, M. R., Krishnan, R., Sankar, S., Unnikrishnan, A. S. and Pai, D. S., Increasing trend of 'break-monsoon' conditions over India - role of ocean-atmosphere processes in the Indian Ocean. IEEE Geosci. Remote Sensing, 2009, 6, 332-336.

12. Vishnu, S., Francis, P. A., Shenoi, S. S. C. and Ramakrishna, S. S. V. S., On the decreasing trend of the number of monsoon depressions in the Bay of Bengal. Environ. Res. Lett., 2016, 11, 014011; https://doi.org/10.1088/1748-9326/11/1/014011.

13. Guhathakurta, P. and Rajeevan, M., Trends in the rainfall pattern over India. Int. J. Climatol., 2008, 28, 1453-1469.

14. Thomas, T., Nayak, P. C. and Ghosh, N. C., Irrigation planning for sustainable rain-fed agriculture in the drought-prone Bundelkhand region of Madhya Pradesh, India. J. Water Climate Change, 2014, 5, 408-426.

15. Thomas, T., Nayak, P. C. and Ghosh, N. C., Spatiotemporal analysis of drought characteristics in the Bundelkhand region of Central India using the standardized precipitation index. J. Hydrol. Eng., 2015, 20, 05015004; https://doi.org/10.1061/(ASCE)HE.19435584.0001189.

16. Mallya, G., Mishra, V., Niyogi, D., Tripathi, S. and Govindaraju, R. S., Trends and variability of droughts over the Indian monsoon region. Weather Climate Extremes, 2016, 12, 43-68.

17. Gosain, A. K., Rao, S. and Basuray, D., Climate change impact assessment on hydrology of Indian river basins. Curr. Sci., 2016, 90, 346-353.

18. Kumar, V., Jain, S. K. and Singh, Y., Analysis of long-term rainfall trends in India. Hydrol. Sci. J., 2010, 55, 484-496.

19. Rajeevan, M., Bhate, J. and Jaswal, A. K., Analysis of variability and trends of extreme rainfall events over India using 104 years of gridded daily rainfall data. Geophys. Res. Lett., 2008, 35, L18707; https://doi.org/10.1029/2008GL035143.

20. Roxy, M. K. et al., A threefold rise in widespread extreme rain events over central India. Nat. Commun., 2017, 8, 708; http://dx.doi.org/10.1038/s41467-017-00744-9.
21. Phalguna, M. and Mirajkar, A. B., The trend analysis of rainfall in the Wainganga River Basin, India. Int. J. Eng. Res. Appl., 2018, 8, $72-85$.

22. Kumar, K. K., Kumar, K. R., Ashrit, R. G., Deshpande, N. R. and Hansen, J. W., Climate impacts on Indian agriculture. Int. J. Climatol., 2004, 24, 1375-1393.

23. Prasanna, V., Impact of monsoon rainfall on the total foodgrain yield over India. J. Earth Syst. Sci., 2014, 123, 1129-1145.

24. Mukherjee, J., Das, D. K., Sehgal, V. K., Vashisth, A., Singh, R. and Barari, S. K., South west monsoon and food grain production of India. J. Agric. Phys., 2014, 14, 73-79

25. Selvaraju, R., Impact of El Niño-southern oscillation on Indian foodgrain production. Int. J. Climatol., 2003, 23, 187-206.

26. Subash, N. and Gangwar, B., Statistical analysis of Indian rainfall and rice productivity anomalies over the last decades. Int. J. Climatol., 2014, 34, 2378-2392.

27. Rai, S. K., Behari, P., Satyapriya, A., Rai, K. and Agrawal, R. K., Long term trends in rainfall and its probability for crop planning in two districts of Bundelkhand region. J. Agrometeorol., 2012, 14, 74-78.

28. Rai, S. K., Kumar, S., Rai, A. K. and Palsaniya, D. R., Climate change, variability and rainfall probability for crop planning in few districts of Central India. Atmos. Climate Sci., 2014, 4, 394 403.

29. Deo, K., Tripathi, P., Kumar, A., Singh, K., Mishra, S., Mishra, A. and Singh, A., Trend of rainfall in different sectors of Uttar Pradesh under present scenario of climate change. Int. J. Environ. Sci., 2015, 6, 303-310.

30. Kar, S. K., Thomas, T. and Singh, R. M., Identification of drought prone areas and trend analysis of rainfall phenomenon in Dhasan Basin. Indian J. Dryland Agric. Res. Dev., 2016, 31, 9-14.

31. Jain, V. K., Pandey, R. P., Jain, M. K. and Byun, H. R., Spatiotemporal rainfall trends in the twentieth century for Bundelkhand region, India. J. Water Climate Change, 2017, 8, 441-455.

32. Kumari, M., Singh, O. P. and Meena, D. C., Crop water requirement, water productivity and comparative advantage of crop production in different regions of Uttar Pradesh, India. Int. J. Curr. Microbiol. App. Sci., 2017, 6, 2043-2052.

33. Shepard, D., A two-dimensional interpolation function for irregularly-spaced data. In Proceedings of the 23rd ACM National Conference, New York, USA, 1968, pp 517-524.

34. Machiwal, D. and Jha, M. K., Comparative evaluation of statistical tests for time series analysis: application to hydrological time series. Hydrol. Sci. J., 2008, 53, 353-366.

35. Yeh, C. F., Wang, J., Yeh, H. F. and Lee, C. H., Spatial and temporal streamflow trends in northern Taiwan. Water, 2015, 7, 634-651.

36. Jayawardena, A., Environmental and Hydrological Systems Modeling, CRC Press, Boca Raton, 2014.

37. Buishand, T. A., Some methods for testing the homogeneity of rainfall records. J. Hydrol., 1982, 58, 11-27.

38. Hamed, K. H. and Rao, A. R., A modified Mann-Kendall trend test for autocorrelated data. J. Hydrol., 1998, 204, 182-196.

39. Theil, H., A rank-invariant method of linear and polynomial regression analysis. In Henri Theil's Contributions to Economics and Econometrics. Advanced Studies in Theoretical and Applied Econometrics (eds Raj, B. and Koerts, J.), Springer, Dordrecht, Netherlands, 1992, vol. 23.

40. Sen, P. K., Estimates of the regression coefficient based on Kendall's tau. J. Am. Stat. Assoc., 1968, 63, 1379-1389.

41. Alpert, P. et al., The paradoxical increase of Mediterranean extreme daily rainfall in spite of decrease in total values. Geophys. Res. Lett., 2002, 29, 311-314.

42. Curtarelli, M., Leão, J., Ogashawara, I., Lorenzzetti, J. and Stech, J., Assessment of spatial interpolation methods to map the bathymetry of an Amazonian hydroelectric reservoir to aid in decision making for water management. ISPRS Int. J. Geo. Inf., 2015, 4 , $220-235$. 
43. Boote, K. J., Growth stages of peanut (Arachis hypogaea L.). Pean. Sci., 1982, 9, 35-40.

44. Reddy, T. Y., Reddy, V. R. and Anbumozhi, V., Physiological responses of groundnut (Arachis hypogea L.) to drought stress and its amelioration: a critical review. Plant. Growth Regul., 2003, 41, $75-88$.

45. Oppong-Sekyere, D., Akromah, R., Nyamah, E. Y., Ninfaa, A. D., Braimah, M. M., Akpalu, M. M. and Salifu, A. R. S., Assessment of postharvest practices of groundnuts in northern Ghana based on the participatory rural appraisal technique. J. Sci. Res. Rep., 2016, 10, $1-17$.

46. Niazi, S., In India's parched Bundelkhand, drought brings a tide of migration [WWW Document]; https://www.preventionweb.net/ news/view/59147 (accessed on 5 October 2018).

47. Saxena, M., Bundelkhand water crisis: Fourth successive drought and vanishing water bodies compound farmer misery, trigger migration [WWW Document]. https://Www.firstpost.com/india/ bundelkhand-water-crisis-fourth-successive-drought-andvanishing-water-bodies-compound-farmer-misery-triggermigration-4468313.html (accessed on 5 October 2018).

48. Bisht, H., Climate Resilient Development in Bundelkhand Region of Madhya Pradesh-Synthesis Report. Development Alternatives, New Delhi, 2013.

49. Mohan, C., Developing Climate Resilient Farming in Bundelkhand [WWW Document]. https://krishijagran.com/news/developing-climate-resilient-farming-in-bundelkhand/ (accessed on 9 October 2018).
50. Rakhecha, P. and Singh, V. P., Applied Hydrometeorology, Capital Publishing Company, New Delhi, 2009.

51. Adamgbe, E. M. and Ujoh, F., Effect of variability in rainfall characteristics on maize yield in Gboko, Nigeria. J. Environ. Prot., 2013, 4, 881-887.

52. Naveen, P., Daniel, K. V., Subramaniyam, P. and Kumar, P. S., Response of irrigated groundnut to agro management. Indian $J$. Agron., 1992, 37, 82-85.

53. IOPEPC, Kharif-2017 Survey of Groundnut Crop. Indian Oilseeds and Produce Export Promotion Council. Govt of India, Mumbai, 2017.

54. Chandrika, V., Parameswari, P. and Sreenivas, G., Effect of sowing time and rainfall distribution on yield of rainfed groundnut (Arachis hypogaea L.) in southern agro-climatic zone of Andhra Pradesh. Legume Res., 2008, 31, 54-56.

ACKNOWLEDGEMENTS. The work presented here is a part of the research project carried out at ICAR-IGFRI, Jhansi, India. We thank ICAR and Director IGFRI, Jhansi for providing the opportunity to carry out this research. We also thank the India Meteorological Department for providing the rainfall data for this research.

Received 11 May 2019; accepted 20 May 2019

doi: $10.18520 /$ cs/v117/i5/794-803 